\title{
Effects of FK506 on Hippocampal CA1 Cells Following Transient Global Ischemia/Reperfusion in Wistar Rat
}

\author{
Zahra-Nadia Sharifi, ${ }^{1}$ Farid Abolhassani, ${ }^{2}$ Mohammad Reza Zarrindast, ${ }^{3}$ \\ Shabnam Movassaghi, ${ }^{4}$ Nasrin Rahimian, ${ }^{5}$ and Gholamreza Hassanzadeh ${ }^{2}$ \\ ${ }^{1}$ Institute for Cognitive Science Studies, Pezeshkpour Alley, Vali-e-Asr Street, 15948-34111 Tehran, Iran \\ ${ }^{2}$ Department of Anatomy, School of Medicine, Tehran University of Medical Sciences, Enghelab Street, 14176-13151 Tehran, Iran \\ ${ }^{3}$ Department of Pharmacology, School of Medicine, Tehran University of Medical Sciences, Enghelab Street, \\ 14176-13151 Tehran, Iran \\ ${ }^{4}$ Department of Anatomy, School of Medicine, Tehran Medical Branch, Islamic Azad University, Shariati Street, \\ Zargandeh Street, 19168 Tehran, Iran \\ ${ }^{5}$ Department of Neurology, Imam Khomeini Hospital, Tehran University of Medical Sciences, Dr. Gharib Street, \\ 14197-31357 Tehran, Iran
}

Correspondence should be addressed to Gholamreza Hassanzadeh, hassanzadeh@tums.ac.ir

Received 22 May 2011; Revised 11 July 2011; Accepted 14 July 2011

Academic Editor: Arijana Lovrencic-Huzjan

Copyright ( $) 2012$ Zahra-Nadia Sharifi et al. This is an open access article distributed under the Creative Commons Attribution License, which permits unrestricted use, distribution, and reproduction in any medium, provided the original work is properly cited.

\begin{abstract}
Transient global cerebral ischemia causes loss of pyramidal cells in CA1 region of hippocampus. In this study, we investigated the neurotrophic effect of the immunosuppressant agent FK506 in rat after global cerebral ischemia. Both common carotid arteries were occluded for 20 minutes followed by reperfusion. In experimental group 1, FK506 (6 mg/kg) was given as a single dose exactly at the time of reperfusion. In the second group, FK506 was administered at the beginning of reperfusion, followed by its administration intraperitoneally (IP) 6, 24, 48, and 72 hours after reperfusion. FK506 failed to show neurotrophic effects on CA1 region when applied as a single dose of $6 \mathrm{mg} / \mathrm{kg}$. The cell number and size of the CA1 pyramidal cells were increased, also the number of cell death decreased in this region when FK506 was administrated $48 \mathrm{~h}$ after reperfusion. This work supports the possible use of FK506 in treatment of ischemic brain damage.
\end{abstract}

\section{Introduction}

Reperfusion injury plays an important role in the brain ischemia cascade, which is involved in stroke and brain trauma. It is due to the inflammatory response of injured tissues [1]. Returned blood flow can reintroduce oxygen which can damage proteins, DNA, and plasma membranes of the cells. Plasma membrane damage may in turn induce the release of more free radicals. These processes may play an important role in redox signaling indirectly and cause cell apoptosis [2].

Certain areas of the brain and certain types of neurons which are more sensitive to cerebral ischemia are pyramidal neurons of the CA1 region of the hippocampus $[3,4]$.

Apoptosis is the most important process in CA1 neurons exposed to transient global ischemia. Apoptotic cell death of neurons can be limited by inhibition of macromolecular synthesis and of caspase activity [5]. Therefore, the attempts have predominantly been concentrated on prevention of acute cell death to help stroke patients. More than one hundred agents have proven to be neuroprotective in experimental models [6].

Unlike the promising results from animal models in preventing these types of cell death, unfortunately, no effective pharmacologic strategy has been found to deal with the problem of ischemia. This may be due to lack of efficacy and presence of unwanted side effects $[7,8]$.

Recently, using immunophilin ligands has been considered as a potential and appropriate strategy for neuroprotection. Since it was observed that tacrolimus (FK506), a useful immunosuppressant used in organ transplantation, provides 
neuroprotection against glutamate-induced neurotoxicity in vitro and prevents hippocampal neuronal damage in a model of transient global ischemia, the importance of immunophilins in the development of neuroprotectors has emerged $[9,10]$.

Neuroimmunophilin ligands are a class of compounds that can be used for the treatment of nerve injuries and neurological diseases. These ligands can readily penetrate the blood-brain barrier and are effective in a variety of animal models of ischemia, traumatic nerve injury, and neurodegenerative disorders in human being [11].

Cyclosporin A and FK-506 have already been used in humans (as immunosuppressant drugs). Both of them exhibit neuroprotective actions, but only FK506 and its derivatives have significant neuroregenerative properties. Tacrolimus is a macrolid antibiotic compound which exhibits immunosuppressant effects and interact with the immunophilin FKBP12 (FK506-binding protein). The resulting complex, in turn, can inhibit calcineurin, a $\mathrm{Ca}^{2+}$ calcium/calmodulin-dependent serin/threonine phosphatase $[12,13]$.

Neuroprotective and neuroregenerative properties of tacrolimus seem to act via different mechanisms, because FK506-related compound that bind to FKBP-12 do not block calcineurin (as an immunosuppressant). Thus, FK506 has the ability to enhance nerve regeneration and acts via a calcineurin-independent mechanism $[11,14,15]$.

Many studies assessed neuroprotective effects of FK506, but little is known about the neurotrophic effects of this drug $[11,15,16]$.

The time of injection may also play an important role in the process of neurogenesis, so comprehensive research regarding the effects of different times of injection seems necessary [17].

In the present study, neurotrophic properties of FK506 in CA1 area of Wistar rat hippocampus were assessed by histological outcome following ischemia/reperfusion in different periods of the drug injection.

\section{Methods}

In this study, we evaluate the effects of repeated doses of FK506 after ischemia at various times (IV injection exactly at the time of reperfusion and repeated IP at 6-24-48-72 hours after reperfusion) on hippocampus CA1 pyramidal cell numbers, diameters and number of apoptotic bodies by using Nissl stain and TUNEL-labeled sections Figure 3.

All of the data was collected from the CA1 sector of the hippocampus. The number of surviving pyramidal cells, their diameters and number of dead cells were counted in control, sham and experimental groups which received single and repeated doses of FK506 in various times of injection.

2.1. Animals. Adult male Wistar rats 12 to 13 weeks old and weighing 250-300 g from the Pharmacology Department of Tehran University of Medical Sciences were used in all experiments. The rats were housed under a 12-hour light/dark cycle. They were allowed free access to food and water.

All of them were housed in animal house for at least 5 days prior to experiments. All experiments were performed at the Department of Anatomy, School of Medicine of Tehran University of Medical Sciences and Institute of Cognitive Science Studies in 2010.

All procedures used in the study were approved by the ethics committee for the use of experimental animals at Institute for Cognitive Science Studies, Tehran, Iran.

2.2. Experimental Groups and Drugs. Animals were divided randomly into 7 groups $(n=35)$ as described below.

(1) Control group: rats only anesthetized by pentobarbital sodium (40 mg/kg).

(2) Sham group: After anesthesia by pentobarbital sodium, common carotid arteries on both sides were occluded for 20 minutes followed by reperfusion.

(3) Experimental Group 1: After anesthesia and ischemia for $20 \mathrm{~min}$ followed by reperfusion, $6 \mathrm{mg} / \mathrm{kg}$ Tacrolimus was injected intravenously (IV) at the beginning of reperfusion phase.

(4) Experimental Group 2: After anesthesia and ischemia for 20 minutes followed by reperfusion, $6 \mathrm{mg} / \mathrm{kg}$ Tacrolimus was injected (IV) at the beginning of reperfusion phase. After 6 hours Tacrolimus was injected intraperitoneally (IP) again with the same dose.

(5) Experimental Group 3: After anesthesia and ischemia for $20 \mathrm{~min}$ followed by reperfusion, $6 \mathrm{mg} / \mathrm{kg}$ Tacrolimus was injected (IV) at the beginning of reperfusion phase. After 24 hours, the injection was repeated with the same dose intraperitoneally.

(6) Experimental Group 4: After anesthesia and ischemia for $20 \mathrm{~min}$ followed by reperfusion, $6 \mathrm{mg} / \mathrm{kg}$ Tacrolimus was injected (IV) at the beginning of reperfusion phase. After 48 hour injection was repeated with the same dose (IP).

(7) Experimental Group 5: After anesthesia and ischemia in the same period, injecting a dose of $6 \mathrm{mg} / \mathrm{kg} \mathrm{Tac}$ rolimus (IV) at the beginning of the reperfusion phase was done. After 72 hours injection was repeated with the same dose (IP).

Rats in groups ((1) to (7)) were sacrificed after 4 days, and all brains were removed for histological assessment (Nissl and TUNEL methods).

FK506 (solution, $5 \mathrm{mg} / \mathrm{mL}$ ampule) was kindly gifted by the Astellas Pharmaceutical Co (Osaka-Japan).

2.3. Surgical Procedures. To induce transient cerebral ischemia, rats were anesthetised with sodium pentobarbital anesthesia $(40 \mathrm{mg} / \mathrm{kg}$, IP). A rectal temperature probe was inserted, and body temperature was monitored and maintained at $37^{\circ} \mathrm{C}$ using heating lamps. Both common carotid arteries were exposed and freed from its carotid sheet, then 
the vagus nerves were carefully separated. Both common carotid arteries were occluded for $20 \mathrm{~min}$ using Yashargil Aneurism microclips.

During ischemia, the animals were monitored for body temperature, loss of righting reflex, and unresponsiveness to gentle touch.

Subsequently, the carotid arteries were released and inspected for immediate reperfusion. Recirculation of blood flow was established by releasing the clips and restoration of blood flow in the carotid arteries was confirmed by observation. Animals were returned to their home cage after the surgery and kept separately for 4 days $(96 \mathrm{~h})$. After this period of time, rats were anesthetized intraperitoneally with pentobarbital sodium $(40 \mathrm{mg} / \mathrm{kg})$ and transcardiac perfusion was performed with heparin $(10 \mathrm{U} / \mathrm{mL})$ in $0.9 \%$ salin, followed by $4 \%$ paraformaldehyde in $0.1 \mathrm{M}$ phosphate buffer $(\mathrm{PH}=7.4)$. Their brains were removed and postfixed in the same fixative for more than 3 days. Brains were rapidly removed and put in the fixator for more than 3 days.

2.4. Histopathologies. Paraffin-embedded coronal sections at different thicknesses were cut for different staining methods, 3 and $10 \mu \mathrm{m}$ thickness for Nissl and Tunel staining respectively, between 2.3 and $5 \mathrm{~mm}$ posterior to bregma fortune.

2.5. Nissl Staining. For Nissl staining, $10 \mu \mathrm{m}$-thick sections were mounted directly onto gelatin-coated glass slides and air-dried. The slides were stained with $1.0 \%$ cresyl violet, dehydrated, and cover-slipped with Entellan. Eight photomicrographs were prepared from each animal (between the level of 2.3 and $5 \mathrm{~mm}$ posterior to bregma fortune according to the paxinos atlas). Three of them were selected and counted at $\times 400$ magnification of light microscope by a blinded investigator. Only cells with an evident nucleus and nucleolus were included. Images were taken at $\times 400$ magnification with a microscope (Olympus $A X-70)$ and analyzed by using image tool 2 software.

2.6. TUNEL Staining. For TUNEL staining, paraffin blocks were cut into $3 \mu \mathrm{m}$ thickness coronal sections. To detect apoptotic cells, TUNEL staining was performed using an In Situ Cell Death Detection Kit (Roche, Mannheim, Germany) according to the manufacturer's protocol. Briefly, the sections were deparaffinized in xylol, rehydrated by successive series of alcohol, washed in phosphate-buffered saline (PBS), and deproteinized (or permeabilized) by proteinase $\mathrm{K}(20 \mu \mathrm{g} / \mathrm{mL})$ for $30 \mathrm{~min}$ at room temperature. Then, the sections were rinsed and incubated with $3 \% \mathrm{H}_{2} \mathrm{O}_{2}$ in methanol for $10 \mathrm{~min}$ in the dark to block endogenous peroxidase (POD) then the sections were incubated in the TUNEL reaction mixture for $60 \mathrm{~min}$ at $37^{\circ} \mathrm{C}$ in humidified atmosphere and rinsed with PBS. Then, sections were visualized by using converter-POD for $30 \mathrm{~min}$ in $37^{\circ} \mathrm{C}$ at humidified atmosphere in the dark then rinsed with PBS and 50-100 $\mu \mathrm{L}$ DAB substrate [diaminobenzidine (DAB)] was added and rinsed with PBS then all slides were mounted by cover slip and analysis by light microscope. Coronal sections of the CA1 area of hippocampus at the level of 2.3 and
$5 \mathrm{~mm}$ posterior to bregma according to the paxinos atlas (four sections per animal) [18] were examined and TUNELpositive cells were quantified using light microscopy at $\times 400$ magnification. Values (per $\mathrm{mm}^{2}$ ) from four sections were averaged to calculate the number of TUNEL-positive cells. All counting procedures were performed blindly.

2.7. Statistical Analysis. The data were expressed as mean \pm standard error of measurement (S.E.M.). Statistical analysis of the data for multiple comparisons were performed by one-way ANOVA (SPSS 13 software program) followed by Tukey's test. Statistical significance was defined as a $P$ value $\leq 0.05$.

\section{Results}

After 20 minutes of bilateral Common Carotid Arteries (CCA) occlusion, marked CA1 cell loss was noticed in all subject groups (Figure 1). We found a statistically significant difference in CA1 cell loss among controls and all other subjects groups except group $6(P=0.233)$. Although marked decrease in CA1 hippocampal region cell diameters was observed after 20 minutes of bilateral CCA occlusion in all groups, differences were statistically significant only for group 2 versus controls $(P=0.03)$.

Figure 2 shows the relationship of repeated injections of FK506 on ischemia reperfusion-induced CA1 cell death in various times on cell diameter.

We next carried out TUNEL staining which detects DNA damage characteristic of apoptosis after bilateral common carotid occlusion for 20 minutes.

The number of TUNEL-positive cells was significantly increased compared with control group in the CA1 region of the hippocampus after ischemia. There was a significant difference between control group versus groups $2(P=$ $0.001)$ and $3(P=0.023)$, which means that apoptotic cells were significantly decreased by repeated injection of FK506 in this region.

Figure 4 shows the relationship of FK506 treatment on number of apoptotic cell bodies in CA1 region in all groups with various times of injection.

Our results show that neurodegenerative changes were not mitigated by a single FK506 application and that repeated applications of tacrolimus ameliorate not only CA1 damage and neurodegeneration, but also have protective effects, which can reduce CA1 cell death.

\section{Discussion}

Our study demonstrates that rats which are subjected to 20min brain ischemia showed loss of the pyramidal cell in number followed by Delayed Neuronal Death (DND) in CA1 region of hippocampus. Our data extends previous findings of the CCO models of animals which showed transient global cerebral ischemia/reperfusion causing neuronal cell death $[19,20]$. 


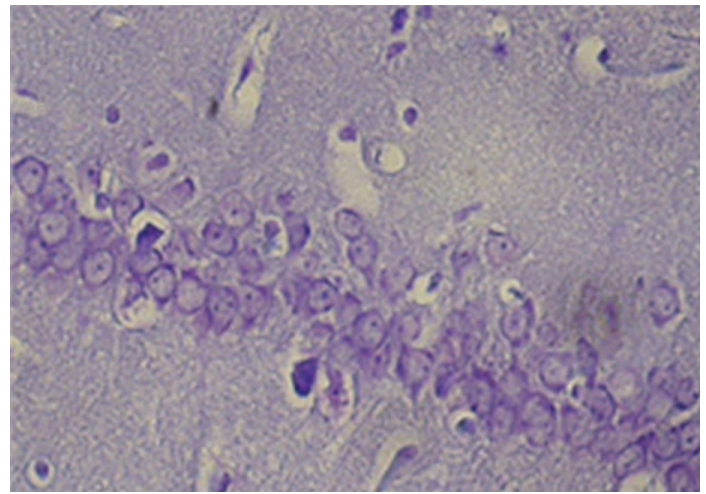

(a)

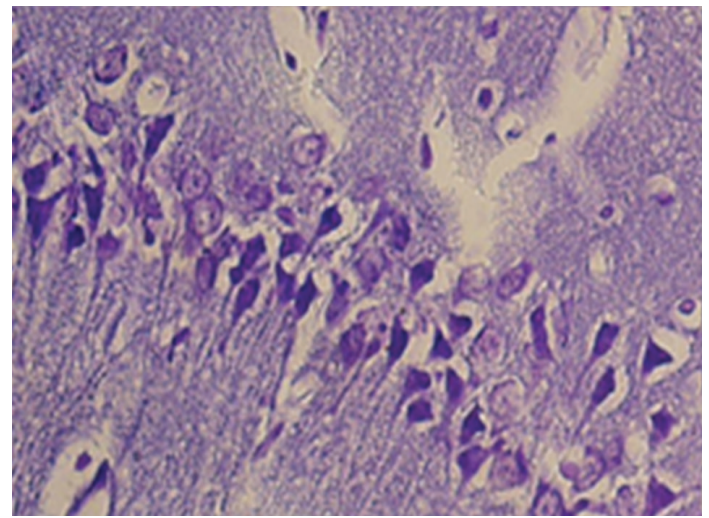

(c)

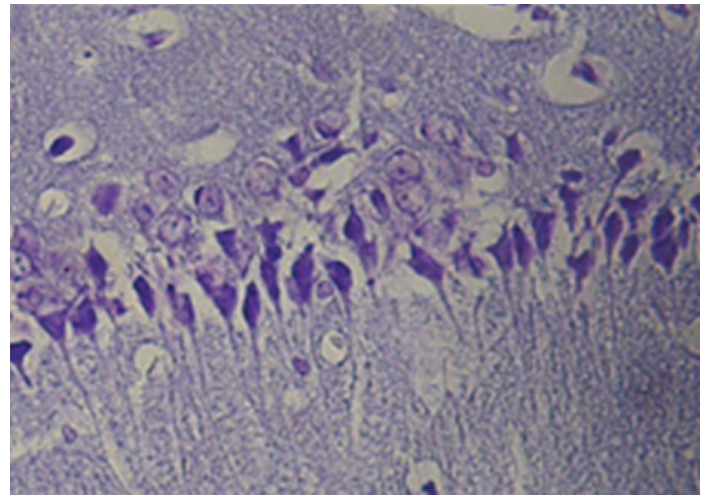

(b)

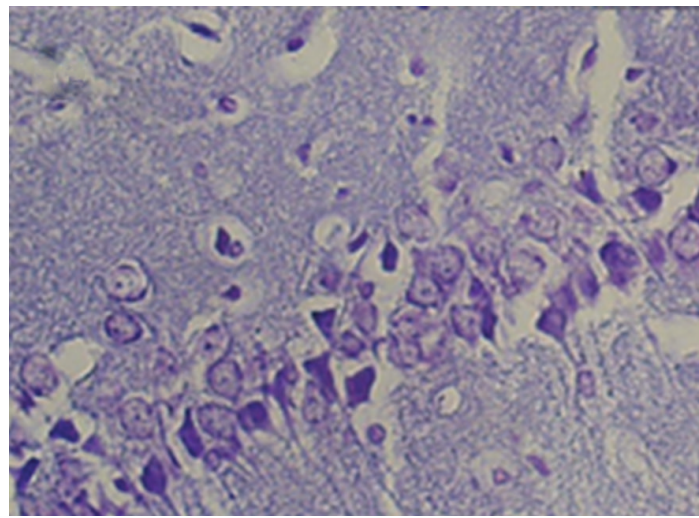

(d)

FIGURE 1: Photomicrographs of coronal sections (cresyl violet stain) of the hippocampus. (a) Control group. (b) Rats subjected to ischemia operation. (c) Ischemia plus single dose of FK506 (IV injection exact the time of reperfusion. (d) Ischemia plus repeated doses of FK506 (IV injection exact the time of reperfusion and IP injection at $48 \mathrm{~h}$ after reperfusion). Scale bar $=30 \mu \mathrm{m}$.

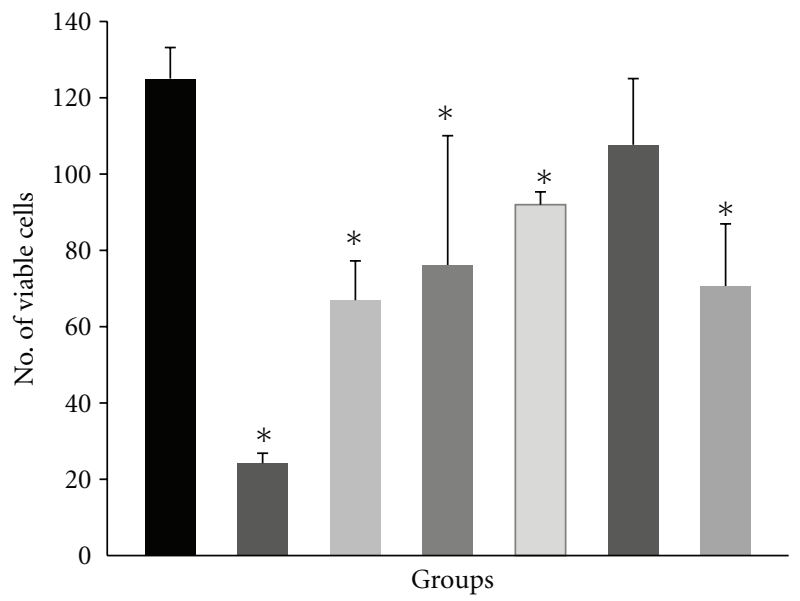

Control

Sham operated

- Single dose at reperfusion time

Repeated dose/ reperfusion time $+6 \mathrm{~h}$ later $\square$ Repeated dose/ reperfusion time +24 h later

Repeated dose/ reperfusion time +48 h later

- Repeated dose/ reperfusion time $+72 \mathrm{~h}$ later

FIGURE 2: The relationship of repeated injections of FK506 on ischemia reperfusion in various time on pyramidal cell number of CA1. ${ }^{*} P<0.05$ versus control and repeated dose/reperfusion time, $48 \mathrm{~h}$ later groups.

In the first experiment, (group 3) a single intravenous injection of FK506 (6 mg/kg) exactly at the time of reperfusion, did not significantly increase the number and size of pyramidal cells of the CA1 region of the hippocampus; however, when the repeated dose of this drug was used after $48 \mathrm{~h}$ with the same concentration, significant increase was observed in the number and size of these cells. our data supported the previous study which demonstrated that repeated FK506, application in contrast to a single injection regime reduces ischemia induced CA1 pyramidal cell [17]. We also found out that the single dose could not decrease the number of Tunel-positive cells in the ischemic region but repeated dose of this drug can decrease the number of Tunel-positive cells in the ischemic region. The potent immunosuppressant was shown to be neuroprotective confirming previous studies [21-23].

There are studies reporting that FK506 can speed up nerve regeneration after peripheral nerve injury in rats [24]. In addition, it increases axonal regeneration following spinal cord injury in a dose-dependent fashion [25]. Applied FK506 enhances the sprouting of axonized central intrinsic neurons such as retinal ganglion cells after optic nerve crush [26]. FK506, and its derivative L-685,818 treatment of rats with crushed sciatic nerves, enhances both functional recovery and regenerated myelinized fibers [27]. FK506 can exert 


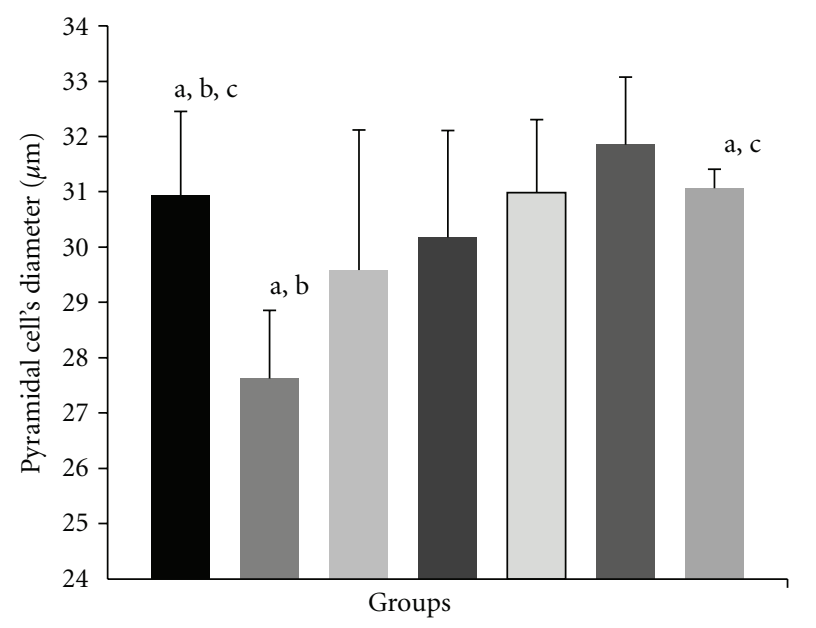

Control

Sham operated

Single dose
Repeated dose/ reperfusion

$$
\text { time }+6 \mathrm{~h} \text { later }
$$

Repeated dose/reperfusion time $+24 \mathrm{~h}$ later

Repeated dose/ reperfusion time $+48 \mathrm{~h}$ later

Figure 3: The effect of FK506 (6 mg/kg injection IV and 4 injections IP in various times) on pyramidal CA1 cells diameters after transient global ischemia. ${ }^{a, b, c} P<0.05$ control (a) versus shamoperated (b) and repeated dose/reperfusion time $+72 \mathrm{~h}$ later (c) groups.

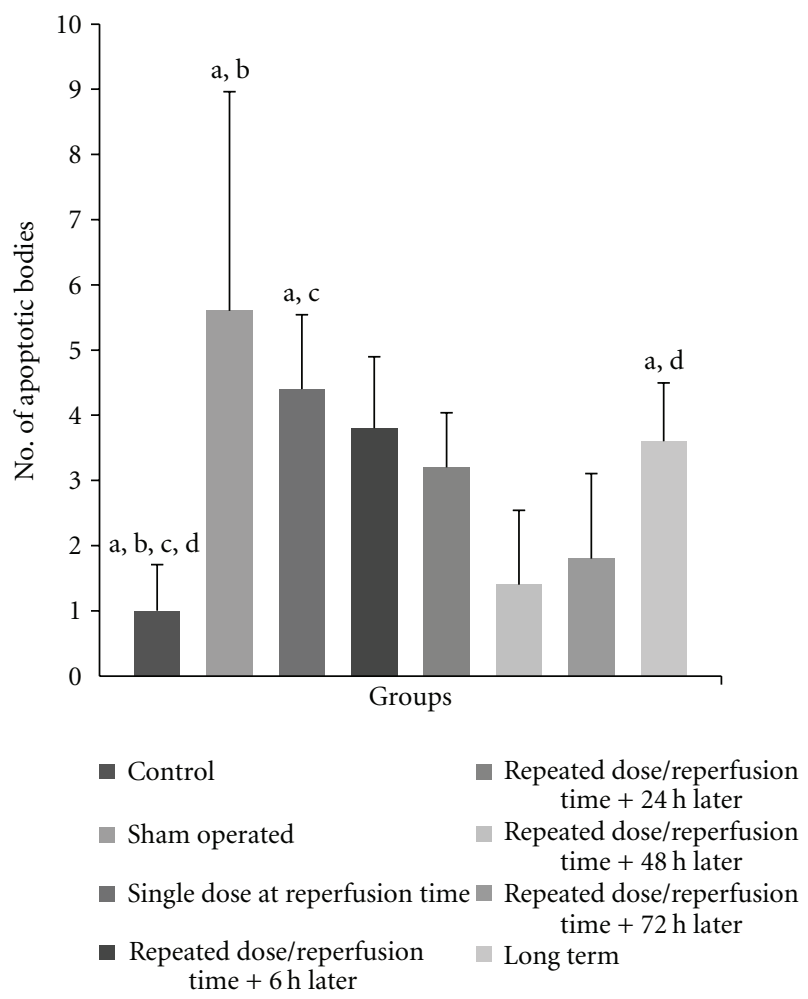

FIgURE 4: Bar graph shows the effect of repeated doses of FK506 on ischemia-induced, hippocampal pyramidal CA1 cell death (apoptotic body) in various times of injection. ${ }^{\mathrm{a}, \mathrm{b}, \mathrm{c}} \mathrm{P}<0.05$ control versus sham, single dose and long term groups.

neurotrophic effects on the penile innervations that promote erectile function recovery in rats after extensive CNS injury [28]. Our findings also show that FK506 can improve the number and size of pyramidal neurons in the hippocampal CA1 region after global transient brain ischemia in a timedependent fashion of repeated injection.

Tissue injury due to ischemia is the result of a pathophysiological cascade which can increase glutamate concentration and stimulate NMDA and other glutamate receptors which can increase $\mathrm{Ca}^{2+}$ entry and cause cell death [29].

DND in the hippocampus following global ischemia was first recognized [30]. Feature of DNA ladders on gel electrophoresis of extracted nuclear DNA is a key feature in apoptotic cells which have been identified after ischemia of 12 or 20 minutes in the rat and 5 or 20 minutes in the gerbils $[31,32]$.

Several studies were done in order to find the mechanism of ischemic cell death, but up to now, the definite mechanism underlying DND followed by ischemia is not found. Calcineurin is one of the most important enzymes which is necessary to regulate the phosphorilation activity of many proteins in neurons $[33,34]$. Brain calcineurin concentration is 3-10 times higher than other tissues [35].

FK506, which is one of the immunosuppressive drugs, binds to the immunophilin FKBP12 (FK506 binding protein) and creates a new complex. This FKBP12-FK506 complex interacts with and inhibits calcineurin [36]. Calcineurin is a common target of FKBP-FK506 complexes [37]. This drug crosses the blood-brain barrier and has neuroprotective effect [38-40]. In this study, it seems that the same mechanism causes this protective effect on the pyramidal neurons of CA1 region.

Several studies have reported that FK506 acts as a neuroprotective agent in several models of focal and global cerebral ischemia in rats, gerbils, and primates, and it can inhibit NO production which contributes to the neuroprotective effect of this drug on DND in the hippocampus [41-46].

Our results are not only in accordance with previous studies, but also shows that FK506 as a neuroprotective agent can ameliorate DND.

Our findings also confirm with the previous finding which reported that a single IV injection of FK506 provided no protection, but this result does not correlate with the study which reported that a single-dose injected (3 or $10 \mathrm{mg} / \mathrm{kg}$ ) IV has neuroprotective effect on pyramidal cells of robust when injected immediately after ischemia [47, 48].

Several studies reported that neurogenesis had occurred after ischemia in the CA1 region [49]. Subgranular and subventricular zones are two sites which are neurogenic areas in intact adult mammalian brain and produce newborn neurons [50]. In normal conditions, there is no neurogenic region, but in animal models of stroke, newborn neurons from the subependymal zone might be induced [51]. The new cells which are generated in subgranular zone of hippocampus differentiate into granular neurons which efficiently develop and change to mature neuronal cells [5254]. 
As mentioned before, there was no statistically significant difference in number of pyramidal cells between the rats that were given repeated doses of tacrolimus after 48 hours and the control group. According to previous studies, further investigations are needed for determining whether these cells are induced by brain endogenous factors or not.

\section{Conclusion}

It was concluded that 20-min brain ischemia showed loss of the pyramidal cells in number and size followed by DND in the hippocampal CA1 region. Repeated dose of FK506 via different mechanisms of action can increase the number and the size of pyramidal cells of the CA1 region of hippocampus and has a neuroprotective effect against DND.

It seems that when FK506 was given repeatedly as a combination of IV (at the beginning of reperfusion phase) plus IP injection ( $48 \mathrm{~h}$ after reperfusion), it may have stimulated the endogenous zones of the brain, and a neurotrophic effect was provided. Such an effect may depend on a repeated dose protocol.

\section{Conflict of Interests}

The authors report no conflict of interests.

\section{Acknowledgments}

This work supported by Institute for Cognitive Science Studies, Tehran, Iran. The authors would like to thank Astellas Pharmaceutical Co (Osaka-Japan) for the gift of FK506 and Dr. Hamed Shafaroudi for his technical assistance on the development of this project.

\section{References}

[1] R. K. Narayan, M. E. Michel, B. Ansell et al., "Clinical trials in head injury," Journal of Neurotrauma, vol. 19, no. 5, pp. 503557, 2002.

[2] S. Clark and M. Wayne, "Reperfusion injury in stroke," eMedicine, WebMD, 2005, http://www.emedicine.com/neuro/ topic602.htm.

[3] J. L. Cummings, U. Tomiyasu, S. Read, and D. F. Benson, "Amnesia with hippocampal lesions after cardiopulmonary arrest," Neurology, vol. 34, no. 5, pp. 679-681, 1984.

[4] C. K. Petito, E. Feldmann, W. A. Pulsinelli, and F. Plum, "Delayed hippocampal damage in humans following cardiorespiratory arrest," Neurology, vol. 37, no. 8, pp. 1281-1286, 1987.

[5] H. Hara, R. M. Friedlander, V. Gagliardini et al., "Inhibition of interleukin $1 \beta$ converting enzyme family proteases reduces ischemic and excitotoxic neuronal damage," Proceedings of the National Academy of Sciences of the United States of America, vol. 94, no. 5, pp. 2007-2012, 1997.

[6] V. Hachinski, "Relevance of rodent models of stroke," Archives of Neurology, vol. 53, no. 10, p. 1070, 1996.

[7] J. Grotta, "The current status of neuronal protective therapy : why have all neuronal protective drugs worked in animals but none so far in stroke patients?" Cerebrovascular Diseases, vol. 4, no. 3, pp. 115-120, 1994.
[8] W. Hacke, "Neuroprotection as initial therapy in acute stroke. Third report of an Ad Hoc Consensus Group Meeting. The European Ad Hoc Consensus Group," Cerebrovascular Diseases, vol. 8, no. 1, pp. 59-72, 1998.

[9] T. M. Dawson, J. P. Steiner, V. L. Dawson, J. L. Dinerman, G. R. Uhl, and S. H. Snyder, "Immunosuppressant FK506 enhances phosphorylation of nitric oxide synthase and protects against glutamate neurotoxicity," Proceedings of the National Academy of Sciences of the United States of America, vol. 90, no. 21, pp. 9808-9812, 1993.

[10] M. Drake, H. Friberg, F. Boris-Möller, K. Sakata, and T. Wieloch, "The immunosuppressant FK506 ameliorates ischaemic damage in the rat brain," Acta Physiologica Scandinavica, vol. 158, no. 2, pp. 155-159, 1996.

[11] B. G. Gold, "Neuroimmunophilin ligands: evaluation of their therapeutic potential for the treatment of neurological disorders," Expert Opinion on Investigational Drugs, vol. 9, no. 10, pp. 2331-2342, 2000.

[12] G. S. Hamilton and J. P. Steiner, "Neuroimmunophilin ligands as novel therapeutics for the treatment of degenerative disorders of the nervous system," Current Pharmaceutical Design, vol. 3, no. 4, pp. 405-428, 1997.

[13] S. Wesselborg, D. A. Fruman, J. K. Sagoo, B. E. Bierer, and S. J. Burakoff, "Identification of a physical interaction between calcineurin and nuclear factor of activated T cells (NFATp)," Journal of Biological Chemistry, vol. 271, no. 3, pp. 1274-1277, 1996.

[14] B. G. Gold, "FK506 and the role of immunophilins in nerve regeneration," Molecular Neurobiology, vol. 15, no. 3, pp. 285306, 1997.

[15] T. Noto, M. Ishiye, Y. Furuich et al., "Neuroprotective effect of tacrolimus (FK506) on ischemic brain damage following permanent focal cerebral ischemia in the rat," Molecular Brain Research, vol. 128, no. 1, pp. 30-38, 2004.

[16] T. M. Reeves, L. L. Phillips, N. N. Lee, and J. T. Povlishock, "Preferential neuroprotective effect of tacrolimus (FK506) on unmyelinated axons following traumatic brain injury," Brain Research, vol. 1154, no. 1, pp. 225-236, 2007.

[17] A. Benetoli, R. A. Paganelli, F. Giordani, K. C. M. Lima, L. A. Fávero Filho, and H. Milani, "Effect of tacrolimus (FK506) on ischemia-induced brain damage and memory dysfunction in rats," Pharmacology Biochemistry and Behavior, vol. 77, no. 3, pp. 607-615, 2004.

[18] M. Morita, H. Imai, Y. Liu et al., "FK506-protective effects against trimethyltin neurotoxicity in rats: hippocampal expression analyses reveal the involvement of periarterial osteopontin," Neuroscience, vol. 153, no. 4, pp. 1135-1145, 2008.

[19] P. Saxena, A. Bala, K. Campbell, B. Meloni, Y. d'Udekem, and I. E. Konstantinov, "Does remote ischemic preconditioning prevent delayed hippocampal neuronal death following transient global cerebral ischemia in rats?" Perfusion, vol. 24, no. 3, pp. 207-211, 2009.

[20] G. Wei, K. K. Kibler, R. C. Koehler, T. Maruyama, S. Narumiya, and S. Doré, "Prostacyclin receptor deletion aggravates hippocampal neuronal loss after bilateral common carotid artery occlusion in mouse," Neuroscience, vol. 156, no. 4, pp. 11111117, 2008.

[21] M. Maeda, Y. Furuichi, N. Ueyama et al., "A combined treatment with tacrolimus (FK506) and recombinant tissue plasminogen activator for thrombotic focal cerebral ischemia in rats: increased neuroprotective efficacy and extended therapeutic time window," Journal of Cerebral Blood Flow and Metabolism, vol. 22, no. 10, pp. 1205-1211, 2002. 
[22] Y. Furuichi, K. Katsuta, M. Maeda et al., "Neuroprotective action of tacrolimus (FK506) in focal and global cerebral ischemia in rodents: dose dependency, therapeutic time window and long-term efficacy," Brain Research, vol. 965, no. 1-2, pp. 137-145, 2003.

[23] R. Pardo, E. Colin, E. Régulier et al., "Inhibition of calcineurin by FK506 protects against polyglutamine-huntingtin toxicity through an increase of huntingtin phosphorylation at S421," Journal of Neuroscience, vol. 26, no. 5, pp. 1635-1645, 2006.

[24] X. Li, W. Wang, G. Wei, G. Wang, W. Zhang, and X. Ma, "Immunophilin FK506 loaded in chitosan guide promotes peripheral nerve regeneration," Biotechnology Letters, vol. 32, no. 9, pp. 1333-1337, 2010.

[25] M. S. Wang and B. G. Gold, "FK506 increases the regeneration of spinal cord axons in a predegenerated peripheral nerve autograft," Journal of Spinal Cord Medicine, vol. 22, no. 4, pp. 287-296, 1999.

[26] C. L. Grosskreutz, V. A. Hänninen, M. B. Pantcheva, W. Huang, N. R. Poulin, and A. P. Dobberfuhl, "FK506 blocks activation of the intrinsic caspase cascade after optic nerve crush," Experimental Eye Research, vol. 80, no. 5, pp. 681-686, 2005.

[27] M. Lee, V. B. Doolabh, S. E. Mackinnon, and S. Jost, "FK506 promotes functional recovery in crushed rat sciatic nerve," Muscle and Nerve, vol. 23, no. 4, pp. 633-640, 2000.

[28] A. L. Burnett and R. E. Becker, "Immunophilin ligands promote penile neurogenesis and erection recovery after cavernous nerve injury," Journal of Urology, vol. 171, no. 1, pp. 495-500, 2004.

[29] D. W. Choi, "Excitotoxic cell death," Journal of Neurobiology, vol. 23, no. 9, pp. 1261-1276, 1992.

[30] T. Kirino, "Delayed neuronal death in the gerbil hippocampus following ischemia," Brain Research, vol. 239, no. 1, pp. 57-69, 1982.

[31] B. T. Volpe, T. C. Wessel, B. Mukherjee, and H. J. Federoff, "Temporal pattern of internucleosomal DNA fragmentation in the striatum and hippocampus after transient forebrain ischemia," Neuroscience Letters, vol. 186, no. 2-3, pp. 157-160, 1995.

[32] J. P. MacManus, I. E. Hill, E. Preston, I. Rasquinha, T. Walker, and A. M. Buchan, "Differences in DNA fragmentation following transient cerebral or decapitation ischemia in rats," Journal of Cerebral Blood Flow and Metabolism, vol. 15, no. 5, pp. 728-737, 1995.

[33] J. L. Yakel, "Calcineurin regulation of synaptic function: from ion channels to transmitter release and gene transcription," Trends in Pharmacological Sciences, vol. 18, no. 4, pp. 124-134, 1997.

[34] F. Shibasaki, U. Hallin, and H. Uchino, "Calcineurin as a multifunctional regulator," Journal of Biochemistry, vol. 131, no. 1, pp. 1-15, 2002.

[35] Q. Su, M. Zhao, E. Weber, H. P. Eugster, and B. Ryffel, "Distribution and activity of calcineurin in rat tissuesevidence for post-transcriptional regulation of testis-specific calcineurin B," European Journal of Biochemistry, vol. 230, no. 2, pp. 469-474, 1995.

[36] C. S. Hemenway and J. Heitman, "Calcineurin: structure, function, and inhibition," Cell Biochemistry and Biophysics, vol. 30, no. 1, pp. 115-151, 1999.

[37] J. Liu, J. D. Farmer Jr., W. S. Lane, J. Friedman, I. Weissman, and S. L. Schreiber, "Calcineurin is a common target of cyclophilin-cyclosporin A and FKBP-FK506 complexes," Cell, vol. 66 , no. 4, pp. 807-815, 1991.
[38] T. Arii, T. Kamiya, K. Arii et al., "Neuroprotective effect of immunosuppressant FK506 in transient focal ischemia in rat: therapeutic time window for FK506 in transient focal ischemia," Neurological Research, vol. 23, no. 7, pp. 755-760, 2001.

[39] T. Ide, E. Morikawa, and T. Kirino, "An immunosuppressant, FK506, protects hippocampal neurons from forebrain ischemia in the Mongolian gerbil," Neuroscience Letters, vol. 204, no. 3, pp. 157-160, 1996.

[40] T. Tokime, K. Nozaki, and H. Kikuchi, "Neuroprotective effect of FK506, an immunosuppressant, on transient global ischemia in gerbil," Neuroscience Letters, vol. 206, no. 2-3, pp. 81-84, 1996.

[41] J. Sharkey and S. P. Butcher, "Immunophilins mediate the neuroprotective effects of FK506 in focal cerebral ischaemia," Nature, vol. 371, no. 6495, pp. 336-339, 1994.

[42] H. Uchino, E. Elmer, K. Uchino, O. Lindvall, and B. K. Siesjo, "Cyclosporin A dramatically ameliorates CA1 hippocampal damage following transient forebrain ischaemia in the rat," Acta Physiologica Scandinavica, vol. 155, no. 4, pp. 469-471, 1995.

[43] Y. Yagita, K. Kitagawa, K. Matsushita et al., "Effect of immunosuppressant FK506 on ischemia-induced degeneration of hippocampal neurons in gerbils," Life Sciences, vol. 59, no. 19, pp. 1643-1650, 1996.

[44] K. Tanaka, Y. Fukuuchi, H. Nozaki et al., "Calcineurin inhibitor, FK506, prevents reduction in the binding capacity of cyclic AMP-dependent protein kinase in ischemic gerbil brain," Journal of Cerebral Blood Flow and Metabolism, vol. 17, no. 4, pp. 412-420, 1997.

[45] H. Takamatsu, H. Tsukada, A. Noda et al., "FK506 attenuates early ischemic neuronal death in a monkey model of stroke," Journal of Nuclear Medicine, vol. 42, no. 12, pp. 1833-1840, 2001.

[46] T. Sasaki, J. Hamada, M. Shibata, J. Gotoh, N. Araki, and Y. Fukuuchi, "FK506 abrogates delayed neuronal death via suppression of nitric oxide production in rats," Brain Research, vol. 1009, no. 1-2, pp. 34-39, 2004.

[47] F. Giordani, A. Benetolli, L. A. Favero-Filho, K. C. M. Lima, L. Cestari Jr., and H. Milani, "Tacrolimus (FK506) reduces ischemia-induced hippocampal damage in rats: a 7- and 30day study," Brazilian Journal of Medical and Biological Research, vol. 36, no. 4, pp. 495-502, 2003.

[48] T. Ide, E. Morikawa, and T. Kirino, "An immunosuppressant, FK506, protects hippocampal neurons from forebrain ischemia in the Mongolian gerbil," Neuroscience Letters, vol. 204, no. 3, pp. 157-160, 1996.

[49] T. Mori, T. Wakabayashi, Y. Takamori, K. Kitaya, and H. Yamada, "Phenotype analysis and quantification of proliferating cells in the cortical gray matter of the adult rat," Acta Histochemica et Cytochemica, vol. 42, no. 1, pp. 1-8, 2009.

[50] T. Valente, J. Hidalgo, I. Bolea et al., "A diet enriched in polyphenols and polyunsaturated fatty acids, LMN diet, induces neurogenesis in the subventricular zone and hippocampus of adult mouse brain," Journal of Alzheimer's Disease, vol. 18, no. 4, pp. 849-865, 2009.

[51] T. Yamashita, M. Ninomiya, P. H. Acosta et al., "Subventricular zone-derived neuroblasts migrate and differentiate into mature neurons in the post-stroke adult striatum," Journal of Neuroscience, vol. 26, no. 24, pp. 6627-6636, 2006.

[52] M. F. Eckenhoff and P. Rakic, "Nature and fate of proliferative cells in the hippocampal dentate gyrus during the life span of the rhesus monkey," Journal of Neuroscience, vol. 8, no. 8, pp. 2729-2747, 1988. 
[53] B. B. Stanfield and J. E. Trice, "Evidence that granule cells generated in the dentate gyrus of adult rats extend axonal projections," Experimental Brain Research, vol. 72, no. 2, pp. 399-406, 1988.

[54] H. J. Song, C. F. Stevens, and F. H. Gage, "Neural stem cells from adult hippocampus develop essential properties of functional CNS neurons," Nature Neuroscience, vol. 5, no. 5, pp. 438-445, 2002. 


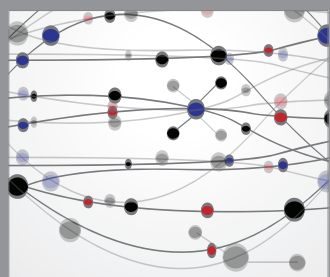

The Scientific World Journal
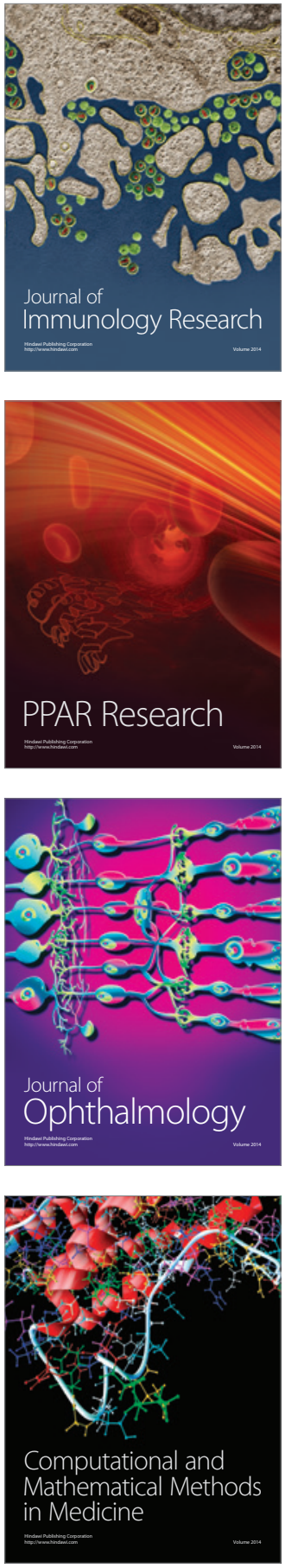

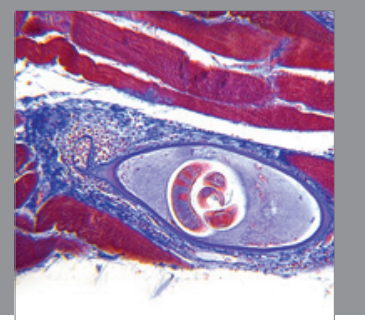

Gastroenterology

Research and Practice
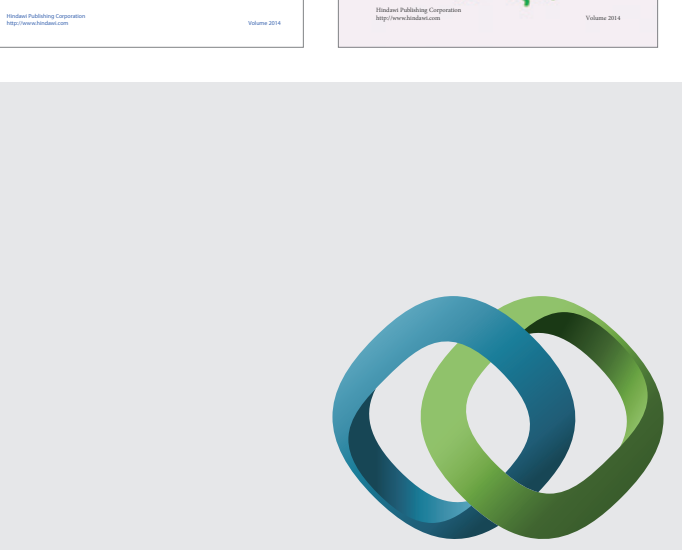

\section{Hindawi}

Submit your manuscripts at

http://www.hindawi.com
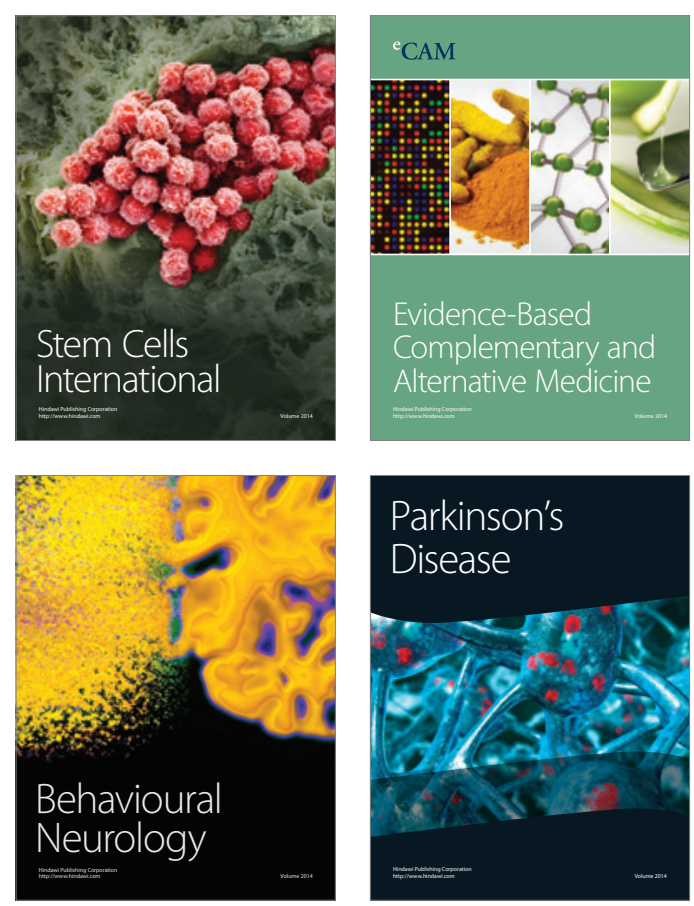

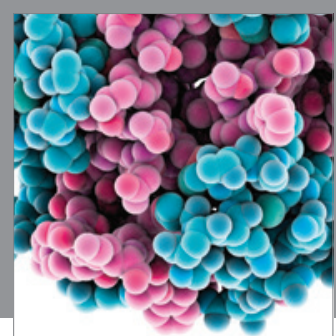

Journal of
Diabetes Research

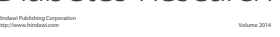

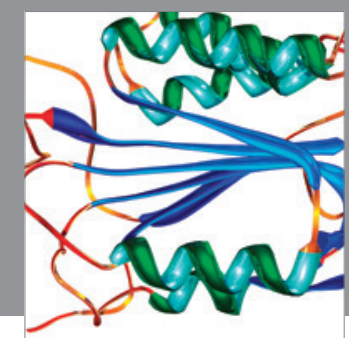

Disease Markers
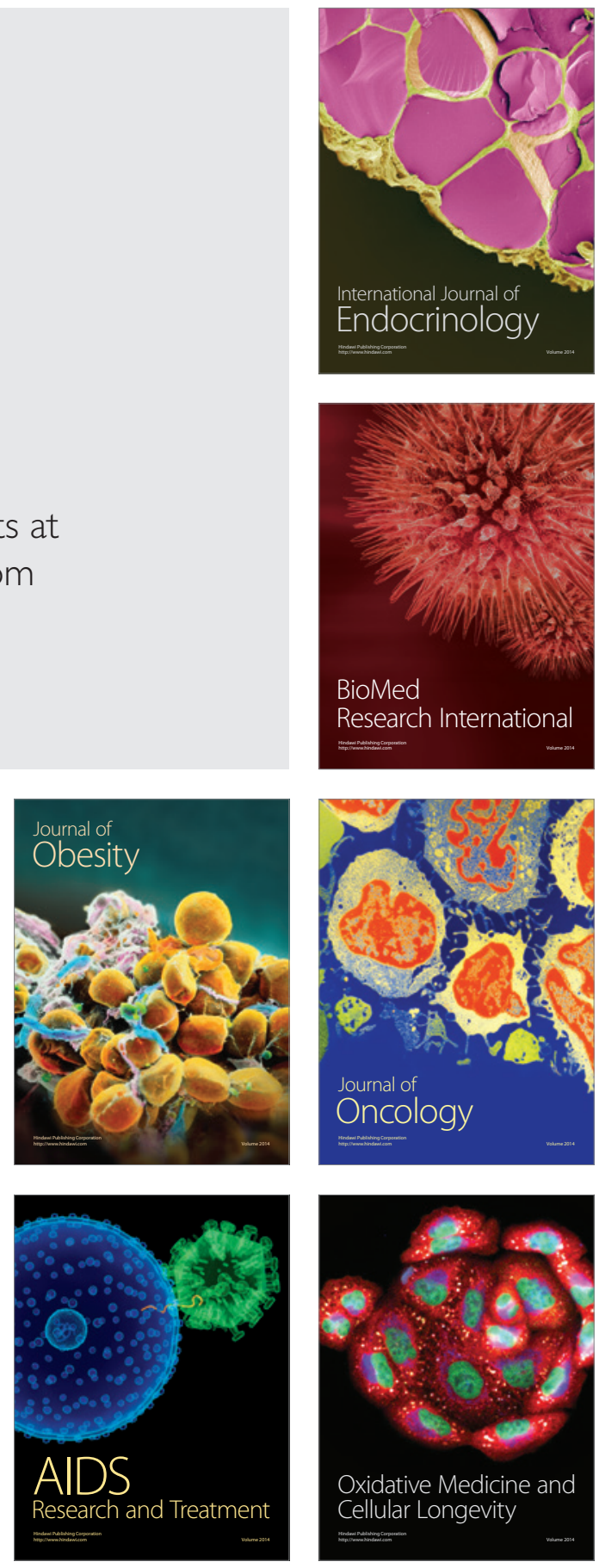